\title{
Evaluating Teachers' Assignment Implementation as School Principals Preparation Program in Indonesia
}

\author{
Muhamad Sholeh, Syunu Trihantoyo \\ Department of Educational Management \\ Universitas Negeri Surabaya \\ Surabaya, Indonesia \\ muhamadsholeh@unesa.ac.id
}

\begin{abstract}
Study about policy education based on its criteria benefits to develop science by having new knowledge to enrich research in public evaluation discipline and educational management research area. Policy evaluation of teachers' assignment as school principals will not only be able to give inputs to ministry of education and culture. But it will also give reinforcement to policy decision to make it successful for what it has been done. The role of principals is very essential to make the school have capability to shape intelligent and competitive Indonesian human capital. School principals as leaders are expected to become contributor to the success of governance reinforcement, accountability and public image of education. Their success to develop educational quality at school is very determined by their professionalism to do their duties, roles and function as principals. To develop their professionalism, it is very imperative to prepare selection of principal candidates. The implementation of proper selection system is hoped to bring about principal candidates who have high credibility since it has important role for education nowadays. It is also hoped that competent principals have capability to build good school cultural organization by emphasizing excellent service to learners and its community.
\end{abstract}

Keywords-educational evaluation; school principals; professionalism

\section{INTRODUCTION}

Education is designed to improve people's quality of Human Resources (HR) to build socio-economic development, preservation of national identity, community welfare, national unity, ignorance freedom, poverty, and national unity binding, national security, health quality and life improvement. This design is achieved based on priority needs in accordance with challenges, obstacles, threats, and demands of the times. In the body of the 1945 Constitution article 31 paragraph 2 states, "The government undertakes and organizes a national teaching system regulated by law". Furthermore, it is also emphasized in the regulation of National Education System Number 20 of 2003 article 3 states, "National education is functioned to develop capabilities and form dignified national character and civilization in order to educate the nation's life to develop potential students to become believers and fear to God Almighty, noble, healthy, knowledgeable, capable, creative, independent, and a democratic and responsible citizen" [5]. The efforts that must be made by the government to improve the quality of education are through increasing the competency of principals, teachers, students and the curriculum renewal based on the development of Science and Technology.

Based on Government Regulation Number 74 of 2008 about teachers as professional educators whose task is to educate, teach, guide, direct, train, evaluate, and gather students in childhood education, formal education, basic education, and high education. Thus, teachers have a strategic role in improving the quality of education. Furthermore, the Regulation of National Education Minister number 28 of 2010 which has been changed to Ministry of Education and Culture number 6 of 2018 about teacher assignment as principal is to educate, teach, guide, direct, train, assess, and compare students. The principal is the most strategic position to mobilize the school component in improving the quality, relevance and competitive education [3]. The principal is the leader who is expected to create successful governance, accountability, and good image of the Indonesian education community. The principal's ability to run duties, roles, and function is the achievement indicator in improving the quality of education. To increase their professionalism, it is very important to prepare a structured preparation for the principal candidates. The implementation of the selection system expected to produce school principal candidates who have high credibility to build a good school culture by prioritizing excellent service for students and school staffs in this current era.

The regulation of National Education Minister number 28 of 2010 which has been changed to Ministry of Education and Culture number 6 of 2018 about teachers' additional assignments as principals, preparation of school principal candidates, promotion process of principals, work duration, continual professional development, performance assessment, and transfer and termination as principals [4]. Here, the writers focus on the policy evaluation of the teacher assignment as principal in the preparation section. The writers think that principal preparation is so important because principals who have been selected in various regions are suspected that their competence is not standardized. This happens because the selection uses the unstandardized instruments so that there is a need to standardize the principal selection process nationally. 
Therefore, the collaboration of all relevant institutions is needed to realize an increase in quality education.

Regulation of national education minister number 28 of 2010 which has been changed to Ministry of Education and Culture number 6 of 2018 about teacher assignment as Principal includes the conditions and stages for being school principals. The teacher must join the program which includes recruitment, selection, education, and training for being school principal candidates. At the recruitment stage, Head of District Education Office informs the needs of the school principal in the next two years and announces to all principals to deliver and encourage potential teachers to participate in the preparation program. Then, the principal candidates are selected administratively and academically. Administrative selection is done through an assessment of documents issued by the competent authorities as proof that the school principal candidates have fulfilled the general requirements. The academic selection is done by making assessment of potential principals (assessed through [8] the results of the assessment of leadership potential and the ability to develop educational leadership papers) and initial mastery of the competencies of school principals in accordance with the laws and regulations.

The evaluation implemented to assess the achievement level of policy program for preparing school principals as mandated by regulation of national education minister number 28 of 2010 [9]. Evaluating the implementation of teacher assignments as principals refers to the standardized system such as definition stage, installation stage, process stage, product stage, and comparison stage program. The study of the policy evaluation implementation of the teacher assignment as principal is very important to determine whether the implementation of National Education Minister Regulation No. 28 of 201028 of 2010 which has been changed to which has been changed to Ministry of Education and Culture number 6 of 2018 succeeds or not. Thus, the selected school principals are expected to work optimally not only as educators but also innovative principals, initiators, motivators, and administrator.

\section{METHOD}

This study is qualitative descriptive approach used to find and review the program, the extent to which the program is implemented, the achievement of objectives, as well as to find out the obstacles. The method is a qualitative using DEM Model (Discrepancy Evaluation Model), a model according to Provus, also called the Gap Model. This is based on the fact that in the implementation of the assignment of teachers as principals it is necessary to look at the gaps that occur between the results expected and those that occur in the field as a measure of the success of recruitment.

The steps of the evaluation approach according to Provus [10], include:

\section{A. Definition Stage}

In the definition stage, the focus of the activity is to formulate objectives, processes or activities, and allocate resources and participants to carry out activities and achieve goals. According to Provus, educational programs are dynamic systems that include inputs (antecedents), processes, and outputs as well as outcomes. The standards or expectations are determined for each of these components. This standard is a program objective which then becomes a criterion in the research activities carried out.

\section{B. Installation Stage}

In the installation phase, the program design is used as a standard to consider the operational steps of the program.

\section{Process Stage}

In the process stage, the evaluation is focused on how to obtain data about the progress of the program participants to determine whether their behavior changes as expected or not. if it is not as expected, it is necessary to make changes to the activities directed to achieve the goal of the behavior change.

\section{Product Stage}

In the product stage, an assessment is done to determine whether goal is achieved or not. Provus distinguishes between immediate outcomes and long term-outcomes.

\section{E. Comparison Stage}

This compares the results and objectives set. In this stage the evaluator writes findings of the gap presented to decision makers, so that they could decide on the continual of candidate principal recruitment program. The finding of gap is evaluated together with evaluators and policy managers so that the recruitment of prospective school principals will run better. like the following: 1) why there are gaps, 2) possible efforts to be taken, 3) which efforts are best to solve the problem

\section{RESULTS AND DISCUSSION}

The result of the study is the description of the evaluated components to answer the research problems such as: a) definition stage, b) installation stage, c) process stage, d) product stage, and e) comparison stage. The findings of five components were obtained using observations, interviews, questionnaires, and documentation. Furthermore, the findings will be interpreted descriptively and supported by theoretical studies (literature) and experts' opinions.

Before presenting the evaluation result, the qualitative data are displayed in tables and graphs. Furthermore, the result from the quantitative data provides a basis for the discrepancy between standards and performance. Then, the qualitative method is used deeply by observation and interviews. The data is analyzed by presenting facts in the descriptive narrative. Furthermore, the evaluation process is done using secondary data, namely the documentation method. The explanation to the study results presents a discrepancy from aspects that are not fulfilled based on the evaluation results. The unfulfilled aspects show that there is discrepancy between performance and specified standard. Therefore, the unfulfilled aspects become the focus of analysis.

Example, the results of the study on policy implementation evaluation of teacher assignment as principals in Bontang City showed that the subjects were administrators of government policies. The implementation of the national education 
minister's regulation in Bontang City has been implemented since 2011.

The preparation of principal candidates in the Bontang City Education Office uses Discrepancy Evaluation Modle (DEM) or the gap model. The results are explained as follows;

\section{A. Definition Stage Evaluation}

The results of program evaluation on preparing school principle candidates are categorized as "good enough". it can be explained as follows:

1) The program was based on Minister of National Education Regulation No. 28 of 2010 which has been changed to Ministry of Education and Culture number 6 of 2018 about teacher assignment as principals needs to be continued even though regional autonomy gives great authority to the Regional Government in education sector. The given authority is still a discourse because it shows two different things: (1) the different recruitment process between one region and another, (2) There is deviation from professionalism principle in the recruitment process.

2) Local governments have the authority to make regulations so that non-procedural appointments can be reduced even the appointment can be eliminated by the appointment system by regulation of National Education minister No. 28 of 2010 which has been changed to Ministry of Education and Culture number 6 of 2018 and 13 of 2007 about school principal competences.

\section{B. Installation Stage Evaluation}

The evaluation results in this stage are categorized as "good enough" this can be explained as follows:

1) The teacher appointment as principal refers to regulation of National Education minister no. 28 of 2010 which has been changed to Ministry of Education and Culture number 6 of 2018 about Teacher assignment as Principal. the process starts from the qualification requirements and preparation stage and appointment process.

2) The teacher assignment as principals refers to service period, continuous professional development, performance assessment of the Principal, including transfers and the assignment period of the teacher as Principal.

\section{Process Stage Evaluation}

The evaluation result in this stage on administration aspect was categorized as "very good", human resources aspect was categorized as "very good", and appointment process aspect was categorized as "not good". This can be explained as follows:

1) The recruitment of school principal candidates in Bontang City Education Office based on administrative aspects has met the following criteria: a) recruitment policy is based on Chapter II article 2 of Regulation of National Education Minister No. 28 of 2010 which has been changed to Ministry of Education and Culture number 6 of 2018 , b) Regulation of National Education Minister no. 13 of 2007, A
Qualification enclosure, c) There is clear support on school principal recruitment, and d) The recruitment is effectively coordinated between Bontang City Education Office, Educational Quality Assurance Agency and The Institute for the Development and Empowerment of School Principals to support the implementation of school recruitment.

2) The recruitment of school principal candidates in Bontang City Education Office on the HR preparation aspects has fulfilled all the required criteria, namely: a) Implementation of recruitment policies based on Article III article 3-8 No. 28 of 2010 , b) The potential of human resources has not been managed optimally to improve the quality of school principals, while criteria c) Education and training for school principals has been managed with the principle of sustainability.

3) The recruitment of school principal candidates in Bontang City Education Office is not good because some criteria have been met with Chapter IV article 9 of regulation of National Education Minister No. 28 of 2010, a) the appointment has been conducted procedurally and established by the City acceptability assessment team, b) The appointment has not run optimally, because the recruitment was implemented before regulation is applied without involving the acceptability assessment team, c) The number of principals who do not meet the competency criteria are still found in the appointment process, but most of them have met the qualifications.

\section{Product Stage Evaluation}

The aspects evaluated on product stage include effectiveness and strategy implementation is categorized as "not good". This can be explained as follows:

1) The recruitment policy of school principal candidates in Bontang City Education Office on the aspect of effectiveness aspects is the most unfulfilled criteria, namely: a) the mastery of principals' competencies, b) low competitiveness, especially in leadership aspects for principals appointed before the Regulation of National Education Minister No. 28 of 2010 and number 6 of 2018, c) The performance of school principals increases but not optimal, because only $40 \%$ of school principals have been appointed using Regulation. However, $40 \%$ of teachers appointed have mastered the competence as regulated in the regulation of National Education minister no. 13 of 2007.

2) The strategy in implementing the recruitment policy of school principals candidates in Bontang City Education Office is categorized as quite good because the principal appointment is designed based on instructions and the needs of school principal candidates. The efforts that were taken are: a) provide opportunities and encourage teachers who fulfill the requirements to be school principal candidates, and b) pass performance assuagement correctly and implemented every year for 4 years so that the qualified and competent principals are selected. 


\section{E. Program Comparison Evaluation}

The implementation system aspect of the comparison stage evaluation was categorized as "good enough" as follows: The recruitment system of school principal candidates in the Bontang City Education Office, shows that teachers who are given additional assignments as principle are ready to return to become teachers after the term ends, but there is a part of the recruitment system that has not yet been implemented, a) being principal is not everlasting position, so that the principal is encouraged to understand article 10 paragraph 5 of the principal's assignment, b) committed to be a teacher after principal position has ended. Here, the principle developed is a life circle in the additional teacher assignment as principal.

\section{CONCLUSION}

To conclude regulation of National Education Minister no. 28 of 2010 and number 6 of 2018 needs to be made perfect because the impact is not comprehensive and to improve the quality of school principals, schools and community schools immediately. Meanwhile, regulation of National Education Minister no. 28 of 2010 and needs to develop a systemic appointment of principal candidates.

Improve the principals' competency appointed before using the Regulation of National Education Minister no. 28 of 2010 and No. 6 of 2018. and for principals who have not mastered Regulation of National Education Minister no. 13 of 2007 should be trained and educated to improve quality of education. Thus, the school principal recruitment without using Regulation of National Education Minister no. 28 of 2010 and No. 6 of 2018 should be limited and give great opportunities for teachers who have very good achievements to be the school principals.

To encourage teachers and involve stakeholders, a more open and transparent recruitment system for school principal candidates needs to be improved and developed to obtain wise leaders. Moreover, the appointed principals' commitment needs to be increased to become a teacher when their position has ended and principals' performance assessment every year for 4 years must be conducted to get the qualified principals.

\section{ACKNOWLEDGMENT}

The authors thank all parties in completing this paper. Likewise, thank you to Surabaya State University for providing financial support so that this paper can be presented in an international forum.

\section{REFERENCES}

[1] G. Eason, B. Noble, and I.N. Sneddon, "On certain integrals of Lipschitz-Hankel type involving products of Bessel functions," Phil. Trans. Roy. Soc. London, vol. A247, pp. 529-551, April 1955. (references)

[2] J. Clerk Maxwell, A Treatise on Electricity and Magnetism, 3rd ed., vol. 2. Oxford: Clarendon, 1892, pp.68-73.

[3] I.S. Jacobs and C.P. Bean, "Fine particles, thin films and exchange anisotropy," in Magnetism, vol. III, G.T. Rado and H. Suhl, Eds. New York: Academic, 1963, pp. 271-350.

[4] K. Elissa, "Title of paper if known," unpublished.

[5] R. Nicole, "Title of paper with only first word capitalized," J. Name Stand. Abbrev., in press.

[6] Y. Yorozu, M. Hirano, K. Oka, and Y. Tagawa, "Electron spectroscopy studies on magneto-optical media and plastic substrate interface," IEEE Transl. J. Magn. Japan, vol. 2, pp. 740-741, August 1987 [Digests 9th Annual Conf. Magnetics Japan, p. 301, 1982].

[7] M. Young, The Technical Writer's Handbook. Mill Valley, CA: University Science, 1989.

[8] Cairns, S. S.. School principals' knowledge and understanding of educator sexual misconduct against students. 2006

[9] Darling-Hammond, L., Barron, B., Pearson, P. D., Schoenfeld, A. H., Stage, E. K., Zimmerman, T. D., ... \& Tilson, J. L.. Powerful learning: What we know about teaching for understanding. John Wiley \& Sons. 2015

[10] M. M. Provus. "The discrepancy evaluation model: An approach to local program improvement and development”. Pittsburgh Public Schools, Pa, 1969 